\title{
Expert Consensus Guidelines for Stocking of Antidotes in Hospitals That Provide Emergency Care
}

Richard C. Dart, MD, PhD; Lewis R. Goldfrank, MD; Brian L. Erstad, PharmD; David T. Huang, MD, MPH;

Knox H. Todd, MD, MPH; Jeffrey Weitz, MD; Vikhyat S. Bebarta, MD; E. Martin Caravati, MD, MPH; Fred M. Henretig, MD; Theodore R. Delbridge, MD, MPH; William Banner, MD, PhD; Sandra M. Schneider, MD; Victoria E. Anderson, MPH*

${ }^{*}$ Corresponding Author. E-mail: victoria.anderson@rmpdc.org.

\begin{abstract}
We provide recommendations for stocking of antidotes used in emergency departments (EDs). An expert panel representing diverse perspectives (clinical pharmacology, medical toxicology, critical care medicine, hematology/oncology, hospital pharmacy, emergency medicine, emergency medical services, pediatric emergency medicine, pediatric critical care medicine, poison centers, hospital administration, and public health) was formed to create recommendations for antidote stocking. Using a standardized summary of the medical literature, the primary reviewer for each antidote proposed guidelines for antidote stocking to the full panel. The panel used a formal iterative process to reach their recommendation for both the quantity of antidote that should be stocked and the acceptable timeframe for its delivery. The panel recommended consideration of 45 antidotes; 44 were recommended for stocking, of which 23 should be immediately available. In most hospitals, this timeframe requires that the antidote be stocked in a location that allows immediate availability. Another 14 antidotes were recommended for availability within 1 hour of the decision to administer, allowing the antidote to be stocked in the hospital pharmacy if the hospital has a mechanism for prompt delivery of antidotes. The panel recommended that each hospital perform a formal antidote hazard vulnerability assessment to determine its specific need for antidote stocking. Antidote administration is an important part of emergency care. These expert recommendations provide a tool for hospitals that offer emergency care to provide appropriate care of poisoned patients. [Ann Emerg Med. 2018;71:314-325.]
\end{abstract}

A podcast for this article is available at www.annemergmed.com.

Copyright @ 2017 by the American College of Emergency Physicians. This is an open access article under the CC BY-NC-ND license (http://creativecommons. org/licenses/by-nc-nd/4.0/).

http://dx.doi.org/10.1016/j.annemergmed.2017.05.021

\section{INTRODUCTION}

Antidotes are important in the care of poisoned patients. When used in a timely and appropriate manner, they limit morbidity and mortality. ${ }^{1}$ Conversely, when unavailable or used inappropriately, the patient may not benefit or may experience harm from the poison or antidote. For example, drugs such as cyanide antidotes can be lifesaving, but only if available in a timely manner and administered before irreversible injury occurs. If they are not immediately available, the patient may succumb to cyanide poisoning, and if used incorrectly, the antidotes can be harmful.

In 2015, US poison centers reported that antidotes were used 184,742 times. ${ }^{2}$ Unfortunately, important antidotes often are not stocked or are stocked in insufficient quantities. Insufficient stocking of a diverse group of antidotes has been documented repeatedly in more than a dozen countries, including the United States, the United Kingdom, and Canada. ${ }^{3-10}$ The Institute for Safe Medication Practice issues Targeted Medication Safety Best Practices for Hospitals. Best Practice 9 states that a hospital should "[e]nsure all appropriate antidotes, reversal agents, and rescue agents are readily available," as well as "[i]dentify which antidotes, reversal agents, and rescue agents should be administered immediately in emergency situations to prevent patient harm." 11

Although the effectiveness of antidotes is often studied rigorously, other factors involved in the use and stocking of antidotes are not often addressed in published studies. For example, the time to antidote delivery is crucial but few studies have been adequately designed and powered to investigate the effect of delay to antidote administration. Researchers may comment on the need for early use of an antidote, but there are rarely rigorous data available to evaluate such a claim.

The recommendations of an expert panel on the stocking of emergency antidotes were published. ${ }^{12,13}$ We have repeated that process in this study for 2 reasons. First, the antidotes available for use have changed substantially since 2009. For example, ethanol USP and the Lilly cyanide antidote kit are no longer commercially available and new antidotes such as idarucizumab have been introduced. Second, recent evidence indicates persistent deficiencies in 
antidote stocking worldwide. ${ }^{3,4,14,15}$ The causes of this serious problem are unknown, but are likely related in part to limited education, inadequate awareness, infrequent use, interruptions in supply, and limited hospital pharmacy resources. Previous studies have found that larger hospitals are more likely to have adequate stocks of antidotes than smaller or rural hospitals. ${ }^{6,16}$ Perceived cost of antidotes based on purchase price, as well as pharmacist and physician unfamiliarity with poisons and their antidotes, may contribute. ${ }^{6,9,17}$ Changes in the types and complexity of antidotes available and toxicologic problems also play a role.

The Joint Commission (TJC) oversees hospital accreditation in the United States, but does not explicitly address antidote stocking. TJC standard MM 02.01.01 reads that medications available for dispensing or administration are selected, listed, and procured according to hospital-defined criteria. Standard MM 2.30 states that emergency medications or supplies, if any, must be consistently available, controlled, and secured. ${ }^{18}$ Individual state governments also regulate antidotes in some cases. The state of California sanctioned a hospital for violating a regulation requiring " ...availability of prescribed medications 24 hours a day." 19 In that case, digoxin Fab was not immediately available for a patient with cardiac glycoside toxicity.

Given the approval of new antidotes, the changes in availability of antidotes, an evolving regulatory environment, and the persistent lack of and chaotic approach to antidote stocking, we performed an evidencebased consensus process to develop recommendations for the stocking of antidotes at hospitals that provide emergency care.

\section{MATERIALS AND METHODS}

\section{Overview}

To produce useful and clinically relevant recommendations despite an evidence base that is incomplete, we used the same approach as in our previous recommendations: a structured analysis of the existing literature by an expert consensus panel. ${ }^{13}$ We purposefully included a wide range of clinicians with extensive experience in the use and stocking of antidotes, as well as hospital administration of clinical activities (Table E1, available online at http://www.annemergmed.com). Recommendations for antidote stocking were created in 2 phases, similar to the development of American College of Emergency Physicians clinical policies. In phase 1, a standardized evidence-based summary of each publication was generated and all summaries were compiled into a comprehensive evaluation for each antidote. Specifically, each article was summarized to include information on study design, number of patients, clinical course, antidote dose, time of antidote administration, patient outcomes, adverse events, and effectiveness of the antidote. Each comprehensive antidote evaluation was then independently reviewed and revised by a primary reviewer from the expert panel. In phase 2, the reviewer presented the evaluation and his or her recommendation to the full panel, and an iterative process was used to achieve consensus. The panel was instructed to specifically address the needs of hospitals that provide emergency care in the United States. Stocking of antidotes for mass casualty events and the specific clinical considerations for administration of each antidote were not included.

\section{Phase 1}

The expert panel was provided with an initial list of antidotes developed by the principal investigator, which was based on the antidotes in the previous consensus recommendations, along with revisions based on current market availability of several drugs and discussion with panel members. The panel deliberated additions and revisions until consensus on the final list to be evaluated was reached.

Using the same search approach as our previous reports, we expanded the literature database since 2008. Relevant published studies were obtained by nonmedical staff with extensive experience in searching and retrieving medical literature. Evidence-based summaries of the medical literature for each antidote were created by a group of researchers, emergency physicians, and clinical toxicologists not involved in the consensus voting process. For each antidote, a standardized evaluation of 5 to 115 pages was created for subsequent assessment by the primary reviewer.

Publications used to create the evaluations were identified with 3 methods: (1) searches for each antidote and its indications, using the US National Library of Medicine's PubMed database (http://www.pubmed.gov), MEDLINE (through Ovid), EMBASE, and the Cochrane Library, limited to "human" and "English" publications within the last 10 years; (2) review of chapter bibliographies for each antidote in one textbook of toxicology ${ }^{20}$; and (3) review of bibliographies of selected articles from the previous 2 methods for additional citations. Each article was classified according to its methodology, using the clinical guideline model of the American College of Emergency Physicians by trained researchers (class I, goodquality randomized clinical trials and good-quality systematic reviews of good-quality randomized trials; class II, prospective nonrandomized clinical trials, cohort, or well-designed case-control studies, good-quality 
observational or volunteer studies; class III, retrospective case series or case studies), and then summarized with a standardized form. ${ }^{21}$

\section{Phase 2}

Each comprehensive literature evaluation developed in phase 1 was provided to one expert panel member serving as the primary reviewer for that antidote. The expert panel was a diverse group of 12 professionals representing various perspectives (Table 1 and Table E1, available online at http://www.annemergmed.com). The principal investigator served as the nonvoting chairperson and selected individuals for the panel according to evidence of previous antidote research or professional experience in regard to the acquisition and use of antidotes. This approach was necessary because there is no formal body or compendium that evaluates candidate antidotes or their appropriate stocking.

The primary reviewers assessed and revised the literature evaluation produced in phase 1 for each assigned antidote, using their knowledge and experience. The primary reviewer could alter the evaluation according to their analysis of the published studies. Each primary reviewer then formed a provisional recommendation in regard to the antidote and presented the revised literature evaluation and his or her recommendation to the entire panel. The panel's deliberations occurred on November 29 to 30, 2016. The evidence-based analysis was formulated to provide information to the panel in regard to the fundamental questions involved in the selection of each antidote:

1. Is the antidote effective?

2. Do the medical benefits of the antidote outweigh its risks?

Table 1. Profile of antidote panel members.

\begin{tabular}{lc}
\hline Discipline or Specialty & No. of Participants \\
\hline Clinical pharmacology & 1 \\
Clinical pharmacy & 1 \\
Critical care medicine & 2 \\
Emergency medicine & 7 \\
Emergency medical services & 1 \\
Hematology/oncology & 2 \\
Hospital administration & 2 \\
Hospital pharmacy & 1 \\
Medical toxicology & 6 \\
Pediatric critical care medicine & 1 \\
Pediatric emergency medicine & 1 \\
Poison center administration & 2 \\
Public health & 2 \\
Categories were self-selected by panel members. The total is greater than 12 because \\
of multiple designations by some individuals. Additional information on the panel's \\
experience is provided in Table E1, available online at http://www.annemergmed. \\
com.
\end{tabular}

If the consensus was affirmative for the first 2 questions, the panel addressed 2 additional questions:

3. Is time an important factor in antidote use?

a. Does the antidote need to be immediately available (ie, available for immediate administration)?

b. Does the antidote need to be available for administration within 60 minutes of the decision to use?

4. What amount of the antidote is needed to treat one patient weighing $100 \mathrm{~kg}$ ?

An iterative process was used to reach consensus on stocking of each antidote. After presentation of an antidote by the primary reviewer and discussion by the entire panel, a vote was taken to determine consensus. Each member could vote in 1 of 3 ways: agreement, disagreement, or strong disagreement. If one or more panel members expressed strong disagreement, discussion was continued and another vote was taken. For all questions, consensus was defined as agreement by at least $75 \%$ of eligible panel members, provided there was no vote of strong disagreement. An antidote was recommended for stocking if the panel consensus was affirmative for the first 2 questions. If agreement could not be reached, the decision was listed as "consensus not reached."

The additional 2 questions were addressed to assist hospitals in determining when an antidote should be available and in what quantity. The term immediately available was defined as available for immediate administration. The panel understood this to mean that the physical location where the drug is stored may vary by institution and by drug preparation requirements and focused on the timing of agent availability, not the location of stocking. The panel's estimate of the antidote amount needed per patient was based on clinical considerations: dose, duration of therapy (8 or 24 hours), use of extracorporeal elimination such as hemodialysis, and other factors. The panel chose to consider one $100-\mathrm{kg}$ patient as the basis for calculating the amount of antidote to stock. This weight was chosen because, according to recent data from National Health and Nutrition Examination Survey, this weight corresponds to the 75 th percentile for men and between the 90th and 95th percentiles for women. ${ }^{22}$

Competing interests were managed proactively and transparently. Each panel member completed a competing interest form for each antidote, disclosing any financial interest or stock ownership or financial support (eg, research grants, consulting agreements) from each antidote manufacturer or marketer for the preceding 10 years. Any relationship (ie, funding for a clinical trial, a single consultation with the company, or any level of equity holding in the company) was considered a competing 
interest. No participant reported equity holdings in a company. One participant reported funding for clinical research and 5 reported previous consulting agreements with an antidote manufacturer during the preceding 10 years. The panel was informed of all competing interests for each antidote as it was considered. Each panel member with a competing interest was allowed to participate in discussion, but was excluded from serving as the primary reviewer and voting for the antidote involved.

\section{RESULTS}

A total of 3,804 articles were retrieved and reviewed; 2,447 articles were used to develop the literature evaluations and provisional recommendations (Figure). Class I evidence was infrequently available, typically to assess the efficacy of the drug. Class II evidence was more commonly available, but again usually focused on effectiveness. Class III evidence was plentiful, but extremely variable. Few articles explicitly addressed the questions of the appropriate time for availability.

Overall, the panel considered 45 antidotes for stocking in hospitals that accept emergency patients. The panel recommended stocking of 44 of these antidotes, with 23 immediately available (Table 2). Antidotes for conditions such as poisoning by an opioid, cardiac glycoside, or

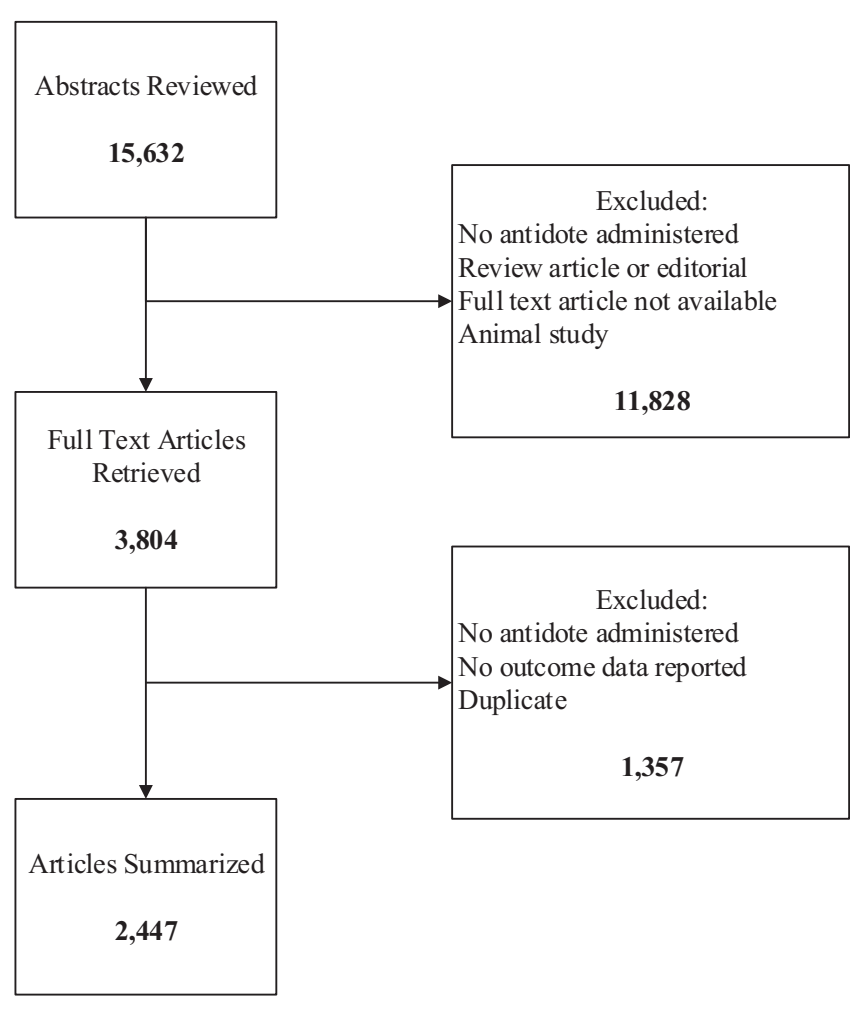

Figure. Article selection. cyanide may be lifesaving if administered before irreversible injury occurs. In most hospitals, this timeframe requires that the antidote be stocked in a location that allows immediate availability. Another 14 antidotes were recommended for availability within 1 hour of the decision to use the antidote (Table 2), allowing the antidote to be stocked in the pharmacy, providing the hospital has an efficient mechanism for prompt delivery of medications from the pharmacy to the emergency department. The panel recommended that an additional 8 antidotes be stocked but not necessarily available within 1 hour of ordering. Among the 45 provisional recommendations made by the primary reviewers, $11(24.4 \%)$ were changed substantially in the final recommendations as a result of panel discussion. Consensus was reached for all antidotes evaluated. Seven drugs were not recommended for consideration by the panel because they were either not approved by the Food and Drug Administration (FDA) or were no longer commercially available. Activated charcoal was not included because it acts by reducing absorption rather than as an antidote and is already widely available.

For some conditions, more than one antidote can effectively treat a poisoning or overdose. The panel identified 3 instances in which more than one effective antidote was available: ethanol or fomepizole for treatment of toxic alcohol exposure, sodium nitrite and sodium thiosulfate or hydroxocobalamin for cyanide toxicity, and 3- or 4-factor prothrombin complex concentrate for reversal of acquired deficiency of the vitamin K-dependent coagulation factors. In these cases, the panel designated a preferred agent, although either agent was recognized as acceptable in meeting the need for stocking. Each preference was determined in the same manner as the decision to recommend stocking of an antidote: by iterative group debate reaching consensus without a vote of strong disagreement. Fomepizole was preferred over ethanol for several reasons: simplicity of use, lack of need for compounding in pharmacy, reduction in medication errors, potential to avoid hemodialysis, and anticipated safety in children. The use of ethanol is further complicated by the lack of a commercially available solution in the United States. Hydroxocobalamin was preferred over sodium nitrite and sodium thiosulfate because of its wider indications, ease of use, and anticipated safety in widespread use. The use of 4-factor prothrombin complex concentrate was preferred over 3-factor prothrombin complex concentrate because of a higher level of available evidence for safety and effectiveness, as well as its having an FDA-approved labeling indication for management of vitamin $\mathrm{K}$ antagonist-associated bleeding. 


\begin{tabular}{l} 
Antidote \\
\hline Acetylcysteine (IV) \\
Acetylcysteine (PO) \\
Antivenin (Latrodectus mactans) \\
Antivenin (Micrurus fulvius) \\
Atropine sulfate \\
Calcium chloride \\
Calcium gluconate \\
Calcium disodium EDTA \\
Calcium trisodium pentetate (calcium \\
DTPA) \\
Centruroides (scorpion) $F\left(a^{\dagger} b_{2}\right)_{2}$
\end{tabular}

Crotalidae polyvalent immune Fab (ovine)

(CroFab; FabAV)

Cyproheptadine

Dantrolene ${ }^{\ddagger}$

Deferoxamine mesylate

Dextrose (D50)

Digoxin immune Fab

Dimercaprol (BAL)

DMSA (succimer)

Ethanol $(\mathrm{PO})^{\ddagger}$ or

fomepizole

Flumazenil

Glucagon hydrochloride ${ }^{\ddagger}$

Glucarpidase

Hydroxocobalamin ${ }^{\S}$ or

sodium nitrite and sodium thiosulfate ${ }^{\dagger}$

Idarucizumab

Leucovorin

Levocarnitine ${ }^{\ddagger}$

Lipid emulsion ${ }^{\ddagger}$

Methylene blue

Naloxone hydrochloride

Octreotide $^{\ddagger}$

Physostigmine

Phytonadione (vitamin $\mathrm{K}_{1}$ )
Strength of Evidence

Is the
Drug

Is Time an
Important

Effective? Outweigh Risks?

Should Be

Panel Recommendation

Acetaminophen toxicity

Black widow spider envenomation

Eastern and Texas coral snake envenomation

Organophosphate pesticide or nerve agent

poisoning, carbamate toxicity

Fluoride, calcium channel blocking agent

toxicity

Lead poisoning

Internal contamination with plutonium,

americium, or curium

Scorpion envenomation in pediatrics (A) and adults (B)

North American crotaline snake envenomation

Serotonin toxicity

Malignant hyperthermia

Iron poisoning

Hypoglycemia

Cardiac glycosides toxicity (A) or cardiac steroid toxicity (B)

Heavy metal toxicity (arsenic $[A]$, lead $[B]$,

$$
\text { mercury [C]) }
$$

Heavy metal toxicity (arsenic $[A]$, lead $[B]$, mercury [C])

Methanol or ethylene glycol poisoning

Benzodiazepine toxicity

$\beta$-Blocker, calcium channel blocker toxicity

Methotrexate toxicity

Cyanide poisoning

Reversal of anticoagulant effects of dabigatran

Methotrexate or methanol toxicity

Valproic acid toxicity

Local anesthetic systemic toxicity

Methemoglobinemia

Opioid toxicity

Sulfonylurea-induced hypoglycemia

Anticholinergic syndrome

Reversal of coumarin-induced coagulopathy
Do Medical

Important
Factor?

I

II

II

II

III

III

III

I (A)

III (B)

I I

I

III

III

III

III

III

III

I (A)

I

II

III

Should Be Available the Hospital Within 60 Minutes

Should Be

Yes
Within 60

Yes Yes No

Yes

Yes

Yes

Yes

Yes

No

Yes
Yes

Yes

Yes

Yes

Yes

Yes

No

Yes

Yes

Yes

No

Yes

Yes

Yes

Yes

No

III $(A, C)$

I (B)

III (A)

I (B)
II (C)

II

I (B)

II

II

Yes

Yes

Yes

Yes
Yes
Yes
Yes
Yes
Yes
Yes
Yes
Yes
Yes
Yes
Yes
Yes
Yes
Yes
Yes

Yes
Yes
Yes
Yes
No
Yes
Yes
Yes
Yes
Yes
Yes
Yes
Yes
Yes
Yes
Yes

No
No
Yes
Yes
No
Yes
Yes
Yes
No
No
Yes
Yes
Yes
No
Yes
Yes 
3-factor prothrombin complex concentrate ${ }^{ \pm}$ or

\section{Reversal of acquired coagulation factor} deficiency induced by vitamin $\mathrm{K}$ antagonists

4-factor prothrombin complex concentrate ${ }^{\S}$ Activated prothrombin complex

concentrate $^{\ddagger}$

Prussian blue

Pyridoxine hydrochloride

Sodium bicarbonate

Thallium (A) or radiocesium (B) toxicity

Thiamine

Isoniazid, hydrazine toxicity

Tricyclic antidepressant toxicity (A), urine alkalization for salicylate toxicity (B), or cocaine toxicity $(C)$

Uridine triacetate

Ethylene glycol toxicity (A), thiamine deficiency associated with chronic alcoholism (B)

|

recitabine overdose

$$
\text { toxicity }
$$

IV, Intravenous; PO, oral; EDTA, ethylenediamine tetra-acetate; DTPA, diethylene triamine penta-acetic acid; FabAv, Fab antivenom; BAL, British antilewisite; DMSA, dimercaptosuccinic acid.

*Strength of evidence: class I: good-quality randomized controlled trials and good-quality systematic reviews of good-quality randomized controlled trials; class II: prospective nonrandomized clinical trials, cohort or well-designed case-control studies, good-quality observational or volunteer studies; class III: retrospective case series, case reports.

${ }^{\dagger}$ Both agents should be stocked.

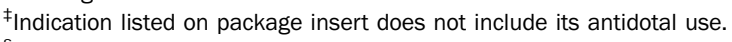

SPreferred agent. 
In 2 instances, the panel recommended the stocking of an antidote for a particular indication, but not for more general usage. Intravenous lipid emulsion was recommended by the panel for use in the setting of local anesthetic systemic toxicity, but not for a broader spectrum of intoxicants because of the panel's consensus that evidence for the latter was currently inconclusive. Additionally, there are no FDA-approved products indicated for the reversal of direct oral anticoagulants, other than idarucizumab for the reversal of dabigatran. Although reversal agents for rivaroxaban, apixaban, and edoxaban are currently under investigation, none has been licensed. In light of the rapidly evolving research in this area and the lack of sufficient evidence to support the effectiveness of 3- or 4-factor prothrombin complex concentrate for this indication, the panel elected not to include prothrombin complex concentrate stocking recommendations for reversal of rivaroxaban, apixaban, or edoxaban or for dabigatran reversal if idarucizumab is unavailable.

The panel recommended the amount of antidote needed to treat a $100-\mathrm{kg}$ patient for a period of either 8 or 24 hours (Table 3). In most cases, the amount of antidote recommended for stocking did not precisely match the package label because of changes in clinical practice since the label content was approved by the FDA and because some antidotes, such as octreotide, are not labeled for use as antidotes.

The panel noted that many considerations can affect the decision to stock an antidote, as well as the amount of antidote that should be stocked. A rigid recommendation for all hospitals is difficult to justify and may lead to underor overstocking. For example, a hospital in an area endemic for crotaline snakes (Crotalus, Agkistrodon, and Sistrurus) should stock antivenom, but the amount recommended for one patient may be insufficient if 2 envenomed patients require simultaneous treatment. To address these situations, the panel recommended that hospitals perform a hazard vulnerability assessment for each antidote, which allows a customized application of the recommendations according to institutional antidote needs (Tables 4 and 5).

\section{LIMITATIONS}

Limited class I and II evidence was available for most antidotes; therefore, many of the panel's recommendations are based on expert analysis and experience. The process attempted to compensate for individual bias by using a diverse and experienced panel, by presenting structured evaluations of medical information, and by prohibiting voting by members with a competing interest. This approach helped to constrain undocumented or unsubstantiated opinion of panel members in 2 ways. First, the published medical evidence was reviewed, and this supported the expectation that the reviewer's conclusions would be evidence based within the limits of available information. Second, the other panel members (who reviewed the evidence simultaneously) acted as a counterbalance against unsubstantiated individual positions of the reviewer.

The panel was chosen by the nonvoting chairman (R.C.D.) according to documented clinical and research expertise, which may have resulted in an unintended bias toward academia. This possibility was counterbalanced by the voting rules that allowed rejection of a recommendation by a single vote of strong disagreement. Several exotic antidotes and antidotes not readily available in North America were not considered. The panel was specifically asked not to anticipate singular or rare events, such as terrorist acts or mass casualty incidents, although individual hospitals may take regional risk factors for such events into account when making stocking decisions according to their own hazard vulnerability assessment. The cost-benefit relationship of antidotes was not assessed because major changes in the marketing of pharmaceuticals means that the price paid by hospitals may vary severalfold and may differ month to month. The intended audience of the recommendations is the group of personnel responsible for providing emergency care in an individual hospital, rather than larger regions, states, or national organizations, given the different needs and resources of such entities.

\section{DISCUSSION}

The panel recommended 44 antidotes for emergency stocking by facilities that provide emergency care in the United States. The recommendations are intended to be interpreted in the context of the potential clinical uses created by the catchment area served by a hospital; special needs for mass casualty events are not addressed in these recommendations.

The major changes from previous recommendations include the addition of 17 antidotes, removal of stocking recommendations for drugs that are not currently commercially available (antivenin [Crotalidae] polyvalent, ethanol solution for injection, botulism antitoxin, and botulism immune globulin [BabyBIG]), and removal of the recommendation to stock amyl nitrite, previously recommended as a component of the Lilly cyanide antidote kit, which is no longer available. Sodium nitrite and sodium thiosulfate are still recommended but are available 
Table 3. Amount of antidote needed to treat one patient weighing $100 \mathrm{~kg}$.

\begin{tabular}{|c|c|c|c|}
\hline \multirow[b]{2}{*}{ Antidote } & \multicolumn{2}{|c|}{ Stocking Recommendation, Hours } & \multirow[b]{2}{*}{ Notes } \\
\hline & 8 & 24 & \\
\hline Acetylcysteine (IV), g & 22 & 30 & Administer intravenously for hepatic failure. \\
\hline Acetylcysteine (PO), g & 28 & 56 & \\
\hline Antivenin ( $L$ mactans), vial & 1 & 1 & $\begin{array}{l}\text { Product has been discontinued by manufacturer; some supplies } \\
\text { remain. }\end{array}$ \\
\hline Antivenin ( $M$ fulvius), vial & 5 & 10 & $\begin{array}{l}\text { Product has been discontinued by manufacturer; some supplies } \\
\text { remain. }\end{array}$ \\
\hline Atropine sulfate, $\mathrm{mg}$ & 45 & 165 & \\
\hline Calcium chloride, $\mathrm{g}$ & 10 & 10 & Do not administer calcium chloride subcutaneously; should be \\
\hline Calcium gluconate, $g$ & 30 & 30 & $\begin{array}{l}\text { administered by central venous route, if possible. Calcium } \\
\text { gluconate may be given by IV, subcutaneous routes. }\end{array}$ \\
\hline Calcium disodium EDTA, $g$ & 0.75 & 2.25 & \\
\hline Calcium trisodium pentetate (calcium DTPA), g & 1 & 1 & \\
\hline Centruroides (scorpion) $F\left(a^{\prime}\right)_{2}$, vial & 3 & 3 & \\
\hline FabAV, vial & 12 & 18 & \\
\hline Cyproheptadine, mg & 20 & 36 & \\
\hline Dantrolene, mg & 800 & 2,000 & Should be available anywhere general anesthesia is performed. \\
\hline Deferoxamine mesylate, $g$ & 12 & 36 & \\
\hline Dextrose (D50), g & 250 & 250 & $\begin{array}{l}\text { D50 as initial treatment may be followed by additional dextrose } \\
\text { at lower concentrations. }\end{array}$ \\
\hline Digoxin immune Fab, vial & 15 & 15 & \\
\hline Dimercaprol (BAL) & $800 \mathrm{mg}$ & $2.4 \mathrm{~g}$ & \\
\hline DMSA (succimer), g & 1 & 3 & \\
\hline Ethanol (PO), g & 180 & 360 & IV ethanol solution for injection may be administered, if available. \\
\hline Fomepizole, g & 1.5 & 4.5 & \\
\hline Flumazenil, mg & 6 & 12 & \\
\hline Glucagon hydrochloride, mg & 90 & 250 & \\
\hline Glucarpidase, U & 5,000 & 5,000 & $\begin{array}{l}\text { Glucarpidase should not be administered until } \geq 2 \mathrm{~h} \text { after } \\
\text { leucovorin. }\end{array}$ \\
\hline Hydroxocobalamin, g & 10 & 10 & $\begin{array}{l}\text { Can be used safely in patients with smoke inhalation. Red color } \\
\text { of drug causes laboratory test interference, technologic } \\
\text { dysfunction of dialyzers, and red discoloration of skin and } \\
\text { urine. }\end{array}$ \\
\hline Sodium nitrite, $\mathrm{mg}$, and & 600 & 600 & Nitrites cause methemoglobinemia and can impair oxygen \\
\hline sodium thiosulfate, $\mathrm{g}$ & 25 & 25 & $\begin{array}{l}\text { delivery; should not be used in smoke inhalation patients with } \\
\text { carbon monoxide poisoning. }\end{array}$ \\
\hline Idarucizumab, g & 5 & 5 & \\
\hline Leucovorin & $300 \mathrm{mg}$ & $1 \mathrm{~g}$ & \\
\hline Levocarnitine, g & 9 & 15 & Administer IV for acute toxicity \\
\hline Lipid emulsion (IV), mL & 1,250 & 1,250 & $\begin{array}{l}\text { Recommendations based on products containing an emulsion of } \\
\text { soybean oil, egg phospholipids, and glycerin. }\end{array}$ \\
\hline Methylene blue, mg & 400 & 600 & \\
\hline Naloxone hydrochloride, mg & 20 & 40 & \\
\hline Octreotide, $\mu \mathrm{g}$ & 75 & 225 & \\
\hline Physostigmine, mg & 4 & 4 & \\
\hline Phytonadione (vitamin $\mathrm{K}_{1}$ ), $\mathrm{mg}$ & 50 & 100 & $\begin{array}{l}\text { Initial dose should be administered IV (not to exceed } 10 \mathrm{mg} \text { ), with } \\
\text { subsequent doses administered PO. Patients presenting with } \\
\text { elevated international normalized ratio and bleeding should } \\
\text { also be treated with prothrombin complex concentrate. }\end{array}$ \\
\hline Potassium iodide, mg & 130 & 130 & \\
\hline Pralidoxime chloride, g & 7 & 18 & \\
\hline Protamine sulfate & $400 \mathrm{mg}$ & $1.2 \mathrm{~g}$ & \\
\hline 3-factor prothrombin complex concentrate, IU & 5,000 & 5,000 & Vitamin $\mathrm{K}_{1} 10 \mathrm{mg} \mathrm{IV}$ should be administered concurrently to \\
\hline 4-factor prothrombin complex concentrate, IU & 5,000 & 5,000 & $\begin{array}{l}\text { maintain clotting factor levels after prothrombin complex } \\
\text { concentrate levels have diminished. }\end{array}$ \\
\hline Activated prothrombin complex concentrate & $\mathrm{N} / \mathrm{A}$ & $\mathrm{N} / \mathrm{A}$ & \\
\hline Prussian blue, g & 12.5 & 25 & \\
\hline Pyridoxine hydrochloride, g & 8 & 24 & \\
\hline Sodium bicarbonate, $\mathrm{g}$ & 63 & 84 & \\
\hline Thiamine & $500 \mathrm{mg}$ & $1.5 \mathrm{~g}$ & \\
\hline Uridine triacetate, g & 20 & 40 & \\
\hline
\end{tabular}


Table 4. Considerations for hazard vulnerability assessment.

\begin{tabular}{|c|c|}
\hline Antidote & Consideration \\
\hline Acetylcysteine (IV) & Antidote for widely available therapeutic agents \\
\hline \multicolumn{2}{|l|}{ Acetylcysteine (PO) } \\
\hline Antivenin ( $L$ mactans) & Geographic/endemic areas \\
\hline Antivenin ( $M$ fulvius) & Geographic/endemic areas \\
\hline Atropine sulfate & Industry, referral patterns from agricultural areas \\
\hline Calcium chloride & Industry, antidote for widely available therapeutic agents \\
\hline \multicolumn{2}{|l|}{ Calcium gluconate } \\
\hline Calcium disodium EDTA & Prevalence of lead risk factors such as old housing, industry using lead products \\
\hline Calcium trisodium pentetate (calcium DTPA) & Receiving hospital for research laboratory \\
\hline Centruroides (scorpion) $\mathrm{F}\left(\mathrm{ab}^{\prime}\right)_{2}$ & Geographic/endemic areas \\
\hline FabAV & Geographic/endemic areas, history/experience with exotic bites, consider simultaneous bite victims \\
\hline Cyproheptadine & All hospitals: serotonin toxicity occurs throughout the United States \\
\hline Dantrolene & All hospitals: malignant hyperthermia occurs throughout the United States \\
\hline Deferoxamine mesylate & All hospitals: acute iron ingestion occurs throughout the United States \\
\hline Dextrose (D50) & All hospitals: acute hypoglycemia occurs commonly throughout the United States \\
\hline Digoxin immune Fab & Antidote for widely available therapeutic agents \\
\hline Dimercaprol (BAL) & Industry, prevalence of heavy metal risk factors \\
\hline DMSA (succimer) & Historical rate of pediatric lead poisoning in hospital service area \\
\hline Ethanol (PO) & All hospitals: ethylene glycol and methanol are common throughout the United States \\
\hline Fomepizole & All hospitals: ethylene glycol and methanol are common throughout the United States \\
\hline Flumazenil & Antidote for widely available therapeutic agents \\
\hline Glucagon hydrochloride & Antidote for widely available therapeutic agents \\
\hline Glucarpidase & Hospital catchment area \\
\hline Hydroxocobalamin & Industry, history, local conditions, community planning, facility service area \\
\hline Sodium nitrite and & Industry, history, local conditions, community planning, facility service area \\
\hline \multicolumn{2}{|r|}{ 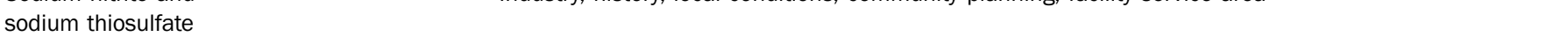 } \\
\hline Idarucizumab & Only approved antidote for reversal of anticoagulant effects of dabigatran \\
\hline Leucovorin & Antidote for widely available therapeutic agent \\
\hline Levocarnitine & Antidote for widely available therapeutic agents \\
\hline Lipid emulsion (IV) & All hospitals: local anesthetic systemic toxicity occurs throughout the United States \\
\hline Methylene blue & All hospitals: methemoglobinemia occurs throughout the United States; high number of causative agents \\
\hline Naloxone hydrochloride & Antidote for widely available and commonly abused agents \\
\hline Octreotide & Antidote for widely available therapeutic agent \\
\hline Physostigmine & Antidote for widely available therapeutic agent \\
\hline Phytonadione (vitamin $\mathrm{K}_{1}$ ) & Antidote for widely available therapeutic agents \\
\hline Potassium iodide & Industry, local conditions \\
\hline Pralidoxime chloride & Industry, referral patterns from agricultural areas \\
\hline Protamine sulfate & Antidote for widely available therapeutic agent \\
\hline 3-factor prothrombin complex concentrate & Antidote for widely available therapeutic agents \\
\hline \multicolumn{2}{|l|}{ 4-factor prothrombin complex concentrate } \\
\hline Prussian blue & Industry \\
\hline Pyridoxine hydrochloride & Industry, history, endemic conditions, community planning, facility service area \\
\hline Sodium bicarbonate & Antidote for widely available therapeutic agents \\
\hline Thiamine & $\begin{array}{l}\text { All hospitals: ethylene glycol toxicity and thiamine deficiency associated with chronic alcoholism occur } \\
\text { throughout the United States }\end{array}$ \\
\hline Uridine triacetate & Prevalence of fluorouracil or capecitabine toxicity risk factors \\
\hline
\end{tabular}

individually or in a 2-component kit without amyl nitrite. Additionally, the recommendations for intravenous acetylcysteine and dimercaprol were updated to more accurately reflect labeled dosing. Finally, the panel reached consensus on stocking recommendations for Prussian blue and for the lack of need for immediate availability of pralidoxime, for which consensus was not previously established.

Insufficient stocking of antidotes needed on an emergency basis has been documented repeatedly in the
United States and other countries. However, it is difficult for hospitals to address this situation because widely accepted guidelines for antidote stocking have not emerged, although certain regional guidelines have been promulgated. ${ }^{10,23}$ National guidelines are difficult to produce because of the heterogeneity of hospital organization and management, as well as the diversity of service area. The expert panel therefore concluded that a mechanism allowing customization of stocking for each hospital should be used. 
Table 5. Hazard vulnerability assessment for emergency antidotes.

\begin{tabular}{|c|c|c|}
\hline Factor & Principle & Example \\
\hline $\begin{array}{l}\text { Pharmaceutical products } \\
\text { used as therapeutic agents }\end{array}$ & $\begin{array}{l}\text { Agents that are widely available should } \\
\text { generally have the antidote stocked because } \\
\text { important geographic differences are not } \\
\text { anticipated. }\end{array}$ & $\begin{array}{l}\text { Acetaminophen } \\
\text { Anticholinergic agents } \\
\text { Benzodiazepines } \\
\text { Dapsone } \\
\text { Digoxin } \\
\text { Iron } \\
\text { Isoniazid } \\
\text { Local anesthetics } \\
\text { New oral anticoagulants } \\
\text { Opioid analgesics } \\
\text { Serotonergic agents } \\
\text { Sulfonylurea hypoglycemic agents } \\
\text { Warfarin }\end{array}$ \\
\hline $\begin{array}{l}\text { Characteristics of hospital } \\
\text { catchment area }\end{array}$ & $\begin{array}{l}\text { Industries, practices, activities, and indigenous } \\
\text { fauna indicate potential need for antidote }\end{array}$ & $\begin{array}{l}\text { Industries generating or using cyanide, heavy metals, hydrogen fluoride, } \\
\text { organophosphorus chemicals, radionuclides, thallium } \\
\text { Chemical transportation routes } \\
\text { Indigenous fauna and flora (snakes, spiders, scorpions, plants) } \\
\text { Agricultural practices (organophosphorus insecticides, cyanide baits, } \\
\quad \text { mining) } \\
\text { Prevalence of oncology patients }\end{array}$ \\
\hline Referral patterns & $\begin{array}{l}\text { Many hospitals accept referrals from remote } \\
\text { areas. These should be included in risk } \\
\text { assessment. }\end{array}$ & $\begin{array}{l}\text { Transfers to urban hospital from agricultural areas } \\
\text { Referral from mining area }\end{array}$ \\
\hline History or experience of use & $\begin{array}{l}\text { Some modes of suicide or abuse become } \\
\text { locally prevalent without a specific industry's } \\
\text { being present }\end{array}$ & $\begin{array}{l}\text { Popularity of cyanide or other specific agents as a suicide agent } \\
\text { Amateur snake keepers in the area }\end{array}$ \\
\hline Anticipated volume of use & $\begin{array}{l}\text { Depending on the characteristics of the area, } \\
\text { more than one victim of a poisoning may be } \\
\text { anticipated. }\end{array}$ & $\begin{array}{l}\text { Multiple casualty incidents (eg, smoke inhalation involving treatment } \\
\text { with cyanide antidotes, large-scale industrial or transportation } \\
\text { incidents, chemical terrorism events) } \\
\text { Indigenous crotaline snakebite in areas with frequent occurrences such } \\
\text { as the southeastern or southwestern United States }\end{array}$ \\
\hline $\begin{array}{l}\text { Anticipated time to } \\
\text { restocking or resupply of } \\
\text { antidote }\end{array}$ & $\begin{array}{l}\text { Time to restocking varies greatly among } \\
\text { hospitals }\end{array}$ & $\begin{array}{l}\text { Hospitals that stabilize and refer patients to other institutions should } \\
\text { stock for the anticipated period. } \\
\text { Hospitals that provide tertiary or definitive treatment should stock for } \\
\text { anticipated duration of illness or until restocking from another } \\
\text { hospital or distributor can occur. } \\
\text { Time to restocking varies by antidote. Some may have prolonged periods } \\
\text { before restocking can occur }\end{array}$ \\
\hline
\end{tabular}

To allow customized application of these guidelines, the panel developed the concept of an antidote hazard vulnerability assessment, an adaptation of the hazard vulnerability assessment required in the United States for accreditation of hospitals by TJC. As defined by TJC, a hazard vulnerability assessment is the identification of potential emergencies and the direct and indirect effects they may have on the hospital's operations and the demand for its services. ${ }^{24}$ This assessment is already required of hospitals that are accredited by TJC and provides a useful framework to assess contingencies presented by poisoned patients.

The hazard assessment concept requires a hospital to formally analyze the types of poisoned patients who may be admitted to their facility, the number of patients who may be admitted, and the amount of each antidote needed. Prioritization of risks is based on available objective data (hospital services and use, demographic information, local industrial uses, availability of antidote at neighboring facilities, and chemical transportation routes, among other factors) that require interaction with appropriate businesses and manufacturers, as well as local, state, and federal agencies. Table 5 provides potential variables that should be considered in this hazard assessment. A hospital should use the hazard assessment process to determine the treatment period for which antidote stocking should occur. Some hospitals may exist in an environment making stabilization and referral of a patient simple and rapid. Other hospitals may be subject to serious transportation difficulties and extreme weather conditions. The process of hazard assessment should include all stakeholders; for example, pharmacy, emergency medicine, clinical toxicology, ICU, risk management, nursing, pharmacy and therapeutic committee, hospital preparedness committee, and hospital 
administration. The regional poison center is an important resource to include in the assessment process.

Many institutions will consider cost in their decision to stock an antidote. We attempted to estimate costs of each antidote, but this is not possible for several reasons. First, the true cost of an antidote has several components. Even the simplest factor, acquisition cost, cannot be accurately determined because each hospital has a different cost owing to purchasing contracts and policies on expired drug return, among other factors. In addition, each antidote has associated costs that vary by institution. For example, one product may require an infusion pump and another monitoring in the ICU. All of these factors and more will need to be considered by each institution.

Some hospitals may forgo stocking of some antidotes for costs or other reasons, optimistically concluding that antidotes can be obtained expeditiously from neighboring facilities in case of urgent need. However, the experience of the expert panel indicates that delays are often encountered during the transfer of antidotes from one hospital to another, even between neighboring hospitals or hospitals under the same management, thereby compromising patient care. Delays can arise from the lack of a dedicated system to facilitate transfer, the infrequent and unplanned nature of these requests, and difficulties prioritizing the delivery of a medication to another facility over other urgent internal hospital orders. Infrequently used antidotes may be difficult to find in an emergency, even within the same facility. To address this issue, some facilities have created a special area in the pharmacy specifically for the stocking of antidotes, whereas other facilities have created a poisoning cart similar to a cardiac arrest cart. $^{10,25}$ It is recommended that each facility ensure that the location and the amount of each antidote stocked are known and accessible to appropriate hospital personnel within the timeframe designated by the antidote expert panel.

Drug shortages are another challenge in antidote stocking. The number of national drug shortages has increased significantly in recent years. In some cases, a second choice for an antidote is available. For example, alcohol may be used for ethylene glycol toxicity if fomepizole becomes unavailable. Other solutions are to contact the regional poison center, which often knows where antidotes are stocked in their service area.

Collaboration with other health care facilities can be successful, although the breakdown of informal antidote transfer agreements can cause patient harm. The use of compounding pharmacies is also a possibility. Each hospital should have formal protocols and order sets in place to guide the use of antidotes, which would have the additional value of complying with Institute for Safe Medication Practice best practices. ${ }^{18}$

These recommendations are not intended to create a standard of care. They were specifically created for consideration by hospitals preparing for clinical demands in their facility. Furthermore, antidote use will change as medical practice evolves and the characteristics of poisoning and overdose change. In addition, each hospital is faced with unique social, political, and geographic challenges that may alter the recommended amount of antidote to stock.

The cost of a specific antidote is considered an important factor in hospital pharmacy purchasing decisions. Although the purchase price of some antidotes can appear expensive, the overall effect on the pharmacy expense budget is smaller than it may appear because many antidotes are infrequently used, and some can be returned unused on expiration. Ironically, some institutions actually stock more antidote than is necessary while understocking others, which creates another reason to perform a hazard vulnerability assessment. ${ }^{23}$ Strategies to minimize costs include reducing inappropriate use and wasteful overstocking, regional stock rotation, and sharing multidose packs between facilities.

The stocking of antidotes has remained a persistent concern for at least 25 years. ${ }^{7}$ The use of the recommendations of the consensus panel, combined with a hospital antidote hazard vulnerability assessment, will allow a hospital to prepare appropriately for the treatment of poisoned patients.

Supervising editor: Matthew D. Sztajnkrycer, MD, PhD

Author affiliations: From the Rocky Mountain Poison and Drug Center, Denver Health and Hospital Authority, Denver, CO (Dart, Anderson); the Ronald O. Perelman Department of Emergency Medicine, New York University School of Medicine, New York, NY (Goldfrank); the Department of Pharmacy Practice and Science, the University of Arizona College of Pharmacy, Tucson, AZ (Erstad); the Multidisciplinary Acute Care Research Organization Center, Departments of Critical Care and Emergency Medicine, University of Pittsburgh, Pittsburgh, PA (Huang); EMLine, Mendoza, Argentina (Todd); the Thrombosis and Atherosclerosis Research Institute, Hamilton General Hospital, Hamilton, Ontario, Canada (Weitz); the Department of Emergency Medicine, Section of Medical Toxicology, University of Colorado School of Medicine, Aurora, CO (Bebarta); the Division of Emergency Medicine, University of Utah School of Medicine, Salt Lake City, UT (Caravati); the Department of Pediatrics, Division of Emergency Medicine, Children's Hospital of Philadelphia, Perelman School of Medicine, University of Pennsylvania, Philadelphia, PA (Henretig); the Department of Emergency Medicine, East Carolina University, Greenville, NC (Delbridge); the Oklahoma Center for Poison and Drug Information, College of Pharmacy, University of Oklahoma, Oklahoma City, OK (Banner); and the Department of Emergency Medicine, Hofstra Northwell School of Medicine, Hempstead, NY (Schneider). 
Authorship: All authors attest to meeting the four ICMJE.org authorship criteria: (1) Substantial contributions to the conception or design of the work; or the acquisition, analysis, or interpretation of data for the work; AND (2) Drafting the work or revising it critically for important intellectual content; AND (3) Final approval of the version to be published; AND (4) Agreement to be accountable for all aspects of the work in ensuring that questions related to the accuracy or integrity of any part of the work are appropriately investigated and resolved.

Funding and support: By Annals policy, all authors are required to disclose any and all commercial, financial, and other relationships in any way related to the subject of this article as per ICMJE conflict of interest guidelines (see www.icmje.org). Funding for this research was provided by BTG International Inc., Boehringer Ingelheim, Rare Disease Therapeutics, and Cumberland Pharmaceuticals to Denver Health and Hospital Authority. Dr. Todd reports receiving consulting fees from Kaleo. Dr. Weitz reports receiving consulting fees from Boehringer Ingelheim. Dr. Bebarta reports receiving consulting fees from BTG International Inc. Dr. Banner reports receiving consulting fees from BTG International Inc. and Pfizer.

Publication dates: Received for publication February 21, 2017. Revision received May 8, 2017. Accepted for publication May 15, 2017. Available online June 29, 2017.

The funding sponsors had no input into the design, definitions, panel proceedings, analysis of the results, or drafting of the article. Rocky Mountain Poison and Drug Center-Denver Health is a nonprofit governmental facility that provides poison and drug information, research, and consulting services to various entities under contract. Clients of the center include a variety of governmental, nongovernmental, and commercial organizations. In addition to the funding sponsors of the Antidote Summit, these include Johnson \& Johnson, Pfizer, and Purdue Pharma.

\section{REFERENCES}

1. Wang RY, Kazzi ZN. Antidotes and rescue therapies. Curr Pharm Biotechnol. 2012;13:1914-1916.

2. Mowry JB, Spyker DA, Brooks DE, et al. 2015 Annual report of the American Association of Poison Control Centers' National Poison Data System (NPDS): 33rd annual report. Clin Toxicol (Phila). 2016;54:924-1109.

3. Abbott V, Creighton M, Hannam J, et al. Access in New Zealand to antidotes for accidental and intentional drug poisonings. J Prim Health Care. 2012;4:100-105.

4. Al-Sohaim S, Awang R, Zyoud S, et al. Evaluate the impact of hospital types on the availability of antidotes for the management of acute toxic exposures and poisonings in Malaysia. Hum Exp Toxicol. 2012;31:274-281.

5. Chyka P, Conner H. Availability of antidotes in rural and urban hospitals in Tennessee. Am J Hosp Pharm. 1994;51:1346-1348.

6. Dart RC, Stark Y, Fulton B, et al. Insufficient stocking of poisoning antidotes in hospital pharmacies. JAMA. 1996;276:1508-1510.

7. Howland M, Weisman R, Sauter D, et al. Nonavailability of poison antidotes. N Engl J Med. 1986;314:927-928.
8. Thanacoody RH, Aldridge G, Laing W, et al. National audit of antidote stocking in acute hospitals in the UK. Emerg Med J. 2013;30:393-396.

9. Gasco L, Rosbolt MB, Bebarta VS. Insufficient stocking of cyanide antidotes in US hospitals that provide emergency care. J Pharmacol Pharmacother. 2013;4:95-102.

10. Pettit HE, McKinney PE, Achusim LE, et al. Toxicology cart for stocking sufficient supplies of poisoning antidotes. Am J Health Syst Pharm. 1999;56:2537-2539.

11. Institute for Safe Medication Practices. 2016-2017 Targeted Medication Safety Best Practices for Hospitals. Institute for Safe Medication Practices; 2016. Available at: https://www.ismp.org/tools/ bestpractices/TMSBP-for-Hospitals.pdf. Accessed June 8, 2017.

12. Dart RC, Goldfrank LR, Chyka PA, et al. Combined evidence-based literature analysis and consensus guidelines for stocking of emergency antidotes in the United States. Ann Emerg Med. 2000;36:126-132.

13. Dart RC, Borron SW, Caravati EM, et al. Expert consensus guidelines for stocking of antidotes in hospitals that provide emergency care. Ann Emerg Med. 2009;54:386-394.e1.

14. Arslan N, Khiljee S, Bakhsh A, et al. Availability of antidotes and key emergency drugs in tertiary care hospitals of Punjab and assessment of the knowledge of health care professionals in the management of poisoning cases. Pak J Pharm Sci. 2016;29:603-607.

15. Sohn CH, Ryoo SM, Lim KS, et al. Kind and estimated stocking amount of antidotes for initial treatment for acute poisoning at emergency medical centers in Korea. J Korean Med Sci. 2014;29: 1562-1571.

16. Juurlink DN, McGuigan MA, Paton TW, et al. Availability of antidotes at acute care hospitals in Ontario. CMAJ. 2001;165:27-30.

17. Sivilotti MLA, Eisen J, Lee J, et al. Can emergency departments not afford to carry essential antidotes? CJEM. 2002;4:23-33.

18. Joint Commission Resources. Revisions to Medication Management Standards Regarding Sample Medications. 2013. Available at: at http://www.jointcommission.org/assets/1/6/SampleMedications_ HAP.pdf. Accessed June 8, 2017.

19. California Health and Human Services Agency Department of Public Health. Hospital Administrative Penalties. Available at: https://archive. cdph.ca.gov/certlic/facilities/Documents/HospitalAdministrative Penalties-2567Forms-LNC/25670liveViewUCLAMedical-SylmarEventE-EW2J11.pdf. Accessed June 8, 2017.

20. Hoffman RS, Howland M, Lewin NA, et al. Goldfrank's Toxicologic Emergencies, 10th ed. New York, NY: McGraw-Hill Education; 2015.

21. Wolf SJ, Heard K, Sloan EP, et al. Clinical policy: critical issues in the management of patients presenting to the emergency department with acetaminophen overdose. Ann Emerg Med. 2007;50:292-313.

22. Fryar CD, Gu Q, Ogden CL, et al. Anthropometric reference data for children and adults: United States, 2011-2014. Vital Health Stat. 2016;3:7-9.

23. Bailey B, Bussieres J-F, Dumont M. Availability of antidotes in Quebec hospitals before and after dissemination of guidelines. Am J Health Syst Pharm. 2003;60:2345-2349.

24. Joint Commission Resources. Emergency Management in Health Care, 3rd ed. Oak Brook, IL: Joint Commission Resources; 2016. Available at: http://www.jcrinc.com/emergency-managementin-health-carethird-edition/.

25. Berndt E. Posted list of emergency drugs and antidotes. Am J Hosp Pharm. 1994;51:2602. 
Table E1. Panelist experience.

\begin{tabular}{|c|c|}
\hline Panelist & Experience \\
\hline Banner & Pediatrics (36 y); pediatric critical care (31 y); medical toxicology (34 y); PhD in pharmacology \\
\hline Bebarta & $\begin{array}{l}\text { Emergency medicine (15y); medical toxicology treating patients at the bedside, conducting preclinical and clinical research, and serving as a } \\
\text { military physician in domestic and combat missions }(13 \mathrm{y})\end{array}$ \\
\hline Caravati & Emergency medicine (20 y); medical toxicology (18 y); poison center medical director (12 y); editor in chief Clinical Toxicology (5 y) \\
\hline Dart & $\begin{array}{l}\text { Emergency medicine (30 y), medical toxicology }(30 \mathrm{y}) \text {, chair of Pharmacy and Therapeutics Committee (10 y), research interest in } \\
\text { antidotes }(25 \mathrm{y})\end{array}$ \\
\hline Delbridge & $\begin{array}{l}\text { Emergency medicine ( } 25 \mathrm{y}) \text {; emergency medical services operations, medical oversight, and research including urban, rural, and air medical } \\
\text { systems ( } 25 \mathrm{y} \text { ); public health: participating in the delivery and evaluation of community health services, evaluating health resource use, and } \\
\text { providing community health education }\end{array}$ \\
\hline Erstad & $\begin{array}{l}\text { Pharmacist in community and academic hospital settings ( } 40 \mathrm{y}) \text {; clinical and research interests pertaining to the safe and cost-effective use of } \\
\text { medication in critical care and emergency medicine settings; editor of the textbook Critical Care Pharmacotherapy }\end{array}$ \\
\hline Goldfrank & $\begin{array}{l}\text { Medical toxicology and emergency medicine in public hospitals and public health department ( } 40 \mathrm{y} \text { ); international toxicology and emergency } \\
\text { medicine in Asia, Africa, South and North America, and Europe (35 y) }\end{array}$ \\
\hline Henretig & $\begin{array}{l}\text { Academic general pediatrics and pediatric emergency medicine (40 y); medical toxicology (36 y); poison center medical director (20 y); } \\
\text { domestic and international disaster relief }(15 \mathrm{y})\end{array}$ \\
\hline Huang & Emergency medicine (16 y); critical care medicine (14 y); emergency medicine-critical care medicine clinical trials (10 y) \\
\hline Schneider & $\begin{array}{l}\text { Emergency medicine ( } 39 \mathrm{y}) \text {, internal medicine }(2.5 \mathrm{y}) \text {; toxicology inpatient practice ( } 3 \mathrm{y}) \text {; poison center director ( } 3 \text { y); toxicologic research (10 } \\
\text { y); chair of emergency medicine (14 y); leadership positions in emergency medicine, including American College of Emergency Physicians, } \\
\text { Society for Academic Emergency Medicine, and Association of Academic Chairs in Emergency Medicine }\end{array}$ \\
\hline Todd & $\begin{array}{l}\text { Emergency medicine (30 y); former medical director, Grady Memorial Emergency Center; tenured emergency medicine faculty member at } \\
\text { Emory University School of Medicine, Albert Einstein College of Medicine, and the University of Texas MD Anderson Cancer Center; former } \\
\text { medical officer, National Center for Injury Prevention and Control, Centers for Disease Control and Prevention; former director, Pain and } \\
\text { Emergency Medicine Institute, Beth Israel Medical Center; former founding vice chair, Department of Emergency Medicine, Emory } \\
\text { University School of Medicine; former founding chair, Department of Emergency Medicine, University of Texas MD Anderson Cancer Center }\end{array}$ \\
\hline Weitz & Hematology and oncology with special emphasis on thrombosis, including reversal of anticoagulants and antiplatelet drugs (35 y) \\
\hline
\end{tabular}

